\title{
RISK FACTORS FOR RECURRENCE OF FEBRILE SEIZURES IN CHILDREN AGED BETWEEN 6 MONTHS TO 5 YEARS OF AGE ADMITTED TO DR. PUNJABRAO DESHMUKH MEDICAL COLLEGE, AMRAVATI
}

\author{
Manish Rane1, Rajendra Nistane2, Pankaj Barabde ${ }^{3}$, Shripad Jahagirdar ${ }^{4}$ \\ ${ }_{1}^{1}$ Final Year Resident, Punjabrao alias Bhausaheb Deshmukh Memorial Medical College, Amravati. \\ ${ }^{2}$ HOD, Department of Pediatrics, Punjabrao alias Bhausaheb Deshmukh Memorial Medical College, Amravati. \\ ${ }^{3}$ Assistant Professor, Department of Pediatrics, Punjabrao alias Bhausaheb Deshmukh Memorial Medical College, Amravati. \\ ${ }^{4}$ Assistant Professor, Department of Pediatrics, Punjabrao alias Bhausaheb Deshmukh Memorial Medical College, Amravati.
}

\begin{abstract}
Febrile seizures (FS) occur in $2 \%$ to $5 \%$ of all children and are most common convulsive event in children younger than 60 month. Recurrence of FS ranges from 21-43\% in different studies and are associated with various risk factors like age of onset of $1^{\text {st }}$ episode of FS less than 1 year, duration and grade of fever, parental consanguinity, family history of FS and epilepsy, male gender and complex FS as initial seizure.
\end{abstract}

AIMS AND OBJECTIVE: The purpose of this study was to evaluate the risk factors and their association for recurrences of febrile seizures in children aged between 6 months to 5 years of age.

MATERIALS \& METHODS: The study design was prospective observational study in which 63 children (6 months to 5 years) presenting with the first episode of FS to Dr. Punjabrao Deshmukh Medical College, Amravati between $1^{\text {st }}$ November 2013 to $31^{\text {st }}$ October 2014 were enrolled in the study. These subjects were followed up for a period of 1 year from the date of $1^{\text {st }}$ episode of FS. RESULTS: In present study 46 out of 63 subjects had recurrence of FS. Male: female ratio in the recurrence group was $0.76: 1$. Family history of FS and epilepsy was present in 34.9\% and 12.6\% respectively. Total $67.34 \%$ subjects with simple FS and $92.85 \%$ with complex FS had recurrence. $69.69 \%$ subjects had FS within 24 hours of onset of fever. Parental consanguinity was found in 14 $(22.2 \%)$ subjects with $p$ value of 0.013 . No association between the number of risk factors and recurrence was found. 22 (34.9\%) out of total 63 subjects were on intermittent FS prophylaxis during the febrile illness and 15 subjects still had recurrence of FS and hence no significant association between recurrence of FS and intermittent prophylaxis for FS was seen.

CONCLUSION: Parental consanguinity and age less than one year for $1^{\text {st }}$ episode of FS were the only significant risk factors indentified for the recurrence of FS. Age of onset of $1^{\text {st }}$ episode of FS less than 1 year, duration of fever, grade of fever, family history of FS and epilepsy, male gender and complex febrile seizure as initial seizure were not found to be significantly associated with recurrence of FS. No significant association between the numbers of risk factors and recurrence of FS was found. Prescribing prophylaxis for FS statistically did not show any benefit in decreasing the frequency nor completely stop the recurrences of FS.

KEYWORDS: Febrile Seizures, Recurrences of Febrile Seizures, Risk Factors for Febrile Seizures.

HOW TO CITE THIS ARTICLE: Manish Rane, Rajendra Nistane, Pankaj Barabde, Shripad Jahagirdar. "Risk factors for Recurrence of Febrile Seizures in Children aged between 6 Months to 5 years of age admitted to Dr. Punjabrao Deshmukh Medical College, Amravati". Journal of Evolution of Medical and Dental Sciences 2015; Vol. 4, Issue 88, November 02; Page: 15340-15344,

DOI: $10.14260 /$ jemds/2015/2182.

INTRODUCTION: American Academy of Pediatrics (AAP) defines a febrile seizure as a seizure accompanied by fever (Temperature $100.4^{\circ} \mathrm{F}$ or $38^{\circ} \mathrm{C}$ by any method), without central nervous system infection, that occurs in infants and children 6 through 60 months of age. Febrile seizures occur in $2 \%$ to $5 \%$ of all children and are most common convulsive event in children younger than 60 month.(1,2) Febrile seizures are usually categorized as either simple or complex. A simple febrile seizure is defined as a self-limiting tonicclonic seizure of short duration $(<15 \mathrm{~min})$ that does not usually recur within the next 24 hours, and that does not leave any post-ictal pathology.

On the other hand, a complex febrile seizure is defined as a focal onset or focal features during the seizure, or a seizure followed by a neurological deficit,

Financial or Other, Competing Interest: None.

Submission 05-10-2015, Peer Review 06-10-2015,

Acceptance 20-10-2015, Published 02-11-2015.

Corresponding Author:

Dr. Manish Rane,

100 Feet Bypass Road, Apex Hospital,

Near Hotel Sujit Garden, Akluj District-Solapur

E-mail: dr.manishrane777@gmail.com

DOI: $10.14260 /$ jemds/2015/2182. prolonged duration ( $>15 \mathrm{~min}$ ), recurrent seizures within the same febrile illness over a 24-hour period.1,2,3 Two to four percent of all children below 5 years suffer from FS but with some variations in various places. ${ }^{4,5}$ Incidence of $10.3 \%$ in South India. ${ }^{6}$ prevalence in India was found out to be 2.27 per 1000 population in North Indian study. ${ }^{7}$ while it was 3.28-5.7/1,000 in South India. ${ }^{8}$ Recurrence of febrile seizure ranges from 21$43 \%$ in different studies. ${ }^{9,10,11}$

Risk factors of recurrence after a first febrile seizure based on various studies are:

1. Age less than one year. $2,11,12,13,14,15$

2. Epilepsy in first-degree relatives. $(2,15,12,16,17,18)$

3. Febrile convulsions in first-degree relatives. $(2,10,11,13,15,14)$

4. A first complex Febrile Seizure - prolonged, multiple and focal. $(2,9,11,13,15,12)$

5. Febrile seizure within an hour of recognized onset of fever. $(2,13,15,16)$

6. Male sex.(2,9)

7. Parental consanguinity. $(2,12)$

The greater the number of risk factors, the higher the recurrence rate and vice versa. 
The AAP has guidelines for evaluation of first simple febrile seizure state that clinicians should work to identify the source of the fever when a child presents within 12 hours of a simple febrile seizure.

Diagnosis is only clinical and usually no investigations or imaging or electroencephalography is necessary.(1) A lumbar puncture is an option in a child 6 to 12 months of age who is not immunized to $\mathrm{H}$ influenza $\mathrm{b}$ and Streptococcu pneumoniae or whose immunization status is not known. A child between 12 and 18 months of age should also be considered for lumbar puncture because clinical picture of meningitis may be subtle. For the well-appearing child after FS, lumbar puncture is usually not conclusive. Children $>18$ months of age, a LP is indicated in the presence of clinical signs and symptoms of meningitis (e.g., neck stiffness, Kernig sign, Brudzinski sign) or if the history and/or physical examination otherwise suggest intracranial infection. EEG performed within 2 week of a FS have nonspecific slowing, usually posteriorly, hence if an EEG is indicated, it is delayed until or repeated after $>2$ week have passed and be restricted to special cases in which epilepsy is highly suspected, and to delineate the type of epilepsy rather than to predict its occurrence. $(2,1)$

The decision to admit should be individualized but admission is usually not necessary. Most children should be observed until they are awake and alert. Children with first FS should be hospitalized if any of the following are present: Lethargy beyond postictal state, Unstable clinical status, Age $<18$ months, Complex features, Uncertain home situation, Unclear follow up. Any child with the slightest suspicion of meningitis should be admitted and investigated. Parents should be counselled about the relative risks of recurrence of febrile seizures and recurrence of epilepsy, teach them how to handle a seizure activity acutely, and give them emotional support.(2)

Patients with febrile convulsion have good outcome. The long term prognosis in terms of subsequent epilepsy, neurological, cognitive \& scholastic ability was not influenced by the type of treatment given. There is no evidence that the treatment to prevent recurrence can prevent the subsequent development of epilepsy. Diazepam, sodium valproate, phenobarbitone \& clobazam have been used to prevent recurrence of febrile convulsion.(2) The numbers of risk factors are directly proportional to the risk of recurrence. A child with two or more risk factors has a more than $30 \%$ recurrence risk at 2 years of age, and that risk doubles with three risk factors.(19)

AIMS AND OBJECTIVE: The purpose of this study was to evaluate the risk factors and their association for recurrences of febrile seizures in children aged between 6 months to 5 years of age.

MATERIALS \& METHODS: The study design was prospective observational study in which 63 children $(6$ months to 5 years) presenting with the first episode of FS to Dr Punjabrao Deshmukh Medical College, Amravati between $1^{\text {st }}$ November 2013 to $31^{\text {st }}$ October 2014 were enrolled in the study. These subjects were followed up for a period of 1 year from the date of $1^{\text {st }}$ episode of FS.

Study Design: The study design was prospective observational study.
Sample Size: By considering the formula.

$\mathrm{n}=4^{*} \mathrm{P}^{*} \mathrm{Q} / \mathrm{L}^{\wedge} 2$.

We have calculated the sample size.

Where $\mathrm{P}$ is prevalence of the disease.

$\mathrm{Q}=100-\mathrm{P}$.

$\mathrm{L}$ is experimental error (5\%).

At $\mathrm{p}-4 \%, \mathrm{Q}=96$.

$\mathrm{N}$ is 61.

This was the manual method by which sample size was 61 and according to the computerized method sample size was 60 , by taking incidence of FS as $4 \% .{ }^{(2)}$ at $5 \%$ precision \& $80 \%$ power, that calculated minimum sample size of 60 by OpenEpi software at $95 \%$ confidence level, with the help of our teachers from Preventive and Social medicine department from our college. Total 63 patients were enrolled in the present study.

Setting: Tertiary care teaching hospital.

Study Population: Children between 6 months to 5 years of age admitted with febrile seizure in Pediatric department which is a tertiary care teaching hospital were followed up.

Duration of Study: 1 year

Subjects presented with the first episode of febrile seizure between $1^{\text {st }}$ November 2013 to $31^{\text {st }}$ October 2014 were enrolled in the study. These subjects were followed up for a period of 1 year from the date of $1^{\text {st }}$ episode of febrile seizure.

Inclusion Criteria: Subjects from 6 months to 5 years of age, presenting with first episode of febrile seizure.

Exclusion Criteria: Subjects with afebrile seizures, evidence of CNS infection, electrolyte abnormalities and underlying neurological disorders.

Operational Definition: Operational definition for the purpose of our study was considered as; the recurrence of febrile seizure was defined as subsequent febrile seizure following a previous episode, with a seizure free period of unspecified duration between the two events. ${ }^{(1)}$

METHODS: This study was conducted on subjects who had presented with first episode of febrile seizures. The study was initiated with the approval of the institutional ethics committee and written informed consent of either parent was taken prior to enrolment. Information was recorded from all subjects, based on the proforma.

All subjects were studied over a period of 1 year from the time of onset of first febrile seizure. Data collection in the present study group was done during follow up in outpatient department and by telephonic conversations every 3 monthly. The parents were also advised to report any recurrence immediately.

\section{The various risk factors that were analyzed are:}

- $\quad$ Age at 1 st episode of febrile seizure.

- Duration of fever before seizure onset.

- $\quad$ Type of febrile seizure - simple/complex.

- Family history of epilepsy/febrile seizure.

- Gender.

- Parental consanguinity. 
The association of each of these various risk factors with recurrence was evaluated. The goal of this study was to evaluate the strength of association of each of these various risk factors with recurrence of febrile seizures and data analysis was done by using SPSS (Statistical Package for social science) version 21.0 and Chi-square test/Fischer's exact test was used to find out the association between qualitative data variables by taking $p$ value of $<0.05$ as significant.

RESULTS: In present study 46 out of 63 subjects had recurrence of FS. Male: female ratio in the recurrence group was $0.76: 1$. Family history of FS and epilepsy was present in $34.9 \%$ and $12.6 \%$ respectively. Total $67.34 \%$ subjects with simple FS and $92.85 \%$ with complex FS had recurrence. $69.69 \%$ subjects had FS within 24 hours of onset of fever. Parental consanguinity was found in $14(22.2 \%)$ subjects with $p$ value of 0.013 . No association between the number of risk factors and recurrence was found. $22(34.9 \%)$ out of total 63 subjects were on intermittent FS prophylaxis during the febrile illness and 15 subjects still had recurrence of FS and hence no significant association between recurrence of FS and intermittent prophylaxis for FS was seen.

DISCUSSION: This study was conducted in the Department of Pediatrics, Dr. Panjabrao Deshmukh hospital \& Research centre, Amravati, during the period of $1^{\text {st }}$ November 2013 to $31^{\text {st }}$ October 2014. The purpose of this study was to determine the association of each of the risk factors with the recurrence of febrile seizures.

The mean age at onset of $1^{\text {st }}$ episode of febrile seizure was 26.72 months which was comparable to the previous studies conducted by Nelson K.B et al.(20) in which the mean age of onset was 23.3 months. Two other studies conducted by Rutter et al.(21) and Fallah Razieh et al.(22) have showed mean age to be 24.3 months. The above mentioned studies have also shown that the onset of $1^{\text {st }}$ episode of febrile seizure before 1 year of age is a risk factor for recurrence, similarly significant association was found between the age of onset and recurrence in the present study. But Ojha et al.(23) did not find any association between the two.

In the present study, mean age of children in the recurrence group was 26.7 months, which is comparable to the study by Chan KK et al.(24) where the mean age of children with recurrence was 19.2 months. The mean recurrence time in present study was $26.72 \pm 13.6$ months. However, Fallah Razieh et al showed a mean recurrence time of $6.7 \pm 5.9$ months.

In the present study, three $(37.5 \%)$ subjects out of total 8 less than one year and rest $43(78.1 \%)$ subjects more than one year had febrile seizure recurrence. $(\mathrm{p}=0.004)$. By using Fisher's exact test p-value $<0.05$ therefore there is significant association between recurrence of febrile seizure and age less than one year for $1^{\text {st }}$ episode of febrile seizure. A study conducted by A Talebian et al.(25) there was also a significant association between the recurrence rates in children less than one year of age ( $p$ value $=0.014$ ).

A study by Fallah Razieh et al showed that children younger than one year and 30\% more than one year had febrile seizure recurrence ( $p$ value $=0.0001$ ) and also the number of the episodes of recurrence of FS was more in those $<1$ year ( $p$ value $=0.04$ ). But 0 jha et al demonstrated no statistically significant association between the two with $p$ value of 0.135 .
In the present study, the male: female ratio in the recurrence group was $0.76: 1$, and by using Chi-square test $p$ value $=0.999$ therefore there is no significant association between recurrence of febrile seizure and gender in the present study. Similarly, male: female ratio of $1.2: 1$ and 1.1:1 was observed by Fallah Razieh et al and Chan KK et al with $p$ value of 0.119 and 0.442 respectively. But Eseigbe et.(26) all demonstrated a clear male preponderance with (M: F, 1.8:1). Also Bessisso et al.(9) found the male gender to be a statistically significant risk factor for recurrence of FS (M: $F=2.25: 1$; $\mathrm{p}=0.02)$.

In the present study, family history of febrile seizure and epilepsy was present in $34.9 \%$ and $12.6 \%$ subjects with $p$ value of 0.255 and 0.311 respectively. The association between the family history of febrile seizure or epilepsy and the recurrence was not found to be statistically significant which is similar to the study conducted by A Talebian et al. A study by Ojha et al also does not show significant relationship between recurrent febrile seizure and family history of seizure disorder or epilepsy. However, Nelson K.B and Berg et al showed a strong association between family history and recurrence.

In the present study, total $67.34 \%$ subjects with simple febrile seizure and $92.85 \%$ with complex febrile seizure had recurrence with $\mathrm{p}$ value of 0.088 therefore there is no significant association between recurrence and type of seizure. A study conducted by Chan KK et al where $30.1 \%$ subjects with simple febrile seizure and $27.58 \%$ with complex febrile seizure had recurrence with $\mathrm{p}$ value of 1.000 and hence there was no significant association between recurrence and type of seizure. Study conducted by Fallah Razieh et al also showed no association between the two with $p$ value $=0.298$ ) and similarly Berg et al showed no significant association between complex febrile seizure and recurrence. But Ojha et al demonstrated a statistically significant association between the two with $\mathrm{p}$ value of 0.022 . Leung et al also found a significant association between complex type of seizures as a risk factor for recurrence of FS.

In the present study recurrence group, $69.69 \%$ subjects had febrile seizure within 24 hours of onset of fever; hence there was no significant association between recurrence of FS and duration of fever with $\mathrm{p}$ value of 0.581 . Similarly, study conducted by Chan KK et al also did not show significant relationship between recurrent febrile seizure and shorter duration of fever before onset of seizure. Talebian et al reported that recurrence rates were $43.7 \%$ and $14.7 \%$ in the two groups of "less than one hour" and "more than one hour "intervals between fever onset and seizure occurrence, respectively. The difference in recurrence rates between these two groups was significant ( $p$ value=0.036). A study by 0jha et al show significant relationship between recurrent febrile seizure and shorter duration of fever before onset of seizure $(p=0.026)$.

In the present study, parental consanguinity was found in $14(22.2 \%)$ subjects. There was statistically significant association with recurrence of FS with $p$ value of 0.013 . A similar result was obtained by Al-Eissa who demonstrated a association between the two. A study in the Turkish Journal of Pediatrics, with positive family history of FS in 1 st and $2^{\text {nd }}$ degree relatives had recurrence in 13 cases.(22) A study conducted by Bessisso et al in which 31\% subjects had parental consanguinity with no statistical significance between the two. Also a study conducted by Chan KK et al also did not show significant relationship between recurrent febrile seizure and parental consanguinity. 
This is in contrast to the study by Anne T Berg et al.(27) which showed that recurrences can be predicted at the time of initial episode by the number of risk factors, i.e. more the number of risk factors, greater is the risk of recurrence. However, the risk factors assessed and study design was different from the present study. In another study Berg et al also showed that the numbers of risk factors are directly proportional to the risk of recurrence.

In the present study, $10.86 \%$ subjects had 1 episode of recurrence and $47.82 \%$ had 2 episodes but the study conducted by Fallah Razieh et al where, 67\% had one, 33\% had two or more episodes of recurrence.

In the present study, $22(34.9 \%)$ out of total 63 subjects were on intermittent FS prophylaxis during the febrile illness and 15 subjects still had recurrence of FS. And $41(65 \%)$ out of total 63 subjects were not on any prophylaxis during the febrile illness, 31 had recurrence of FS. Hence by using Chi-square test $p$ value is 0.562 and hence no significant association between recurrence of FS and intermittent prophylaxis for FS is seen.

CONCLUSION: In present study 46 subjects out of 63 had recurrence of FS. Parental consanguinity was the only significant risk factor indentified for the recurrence of FS. Age of onset of $1^{\text {st }}$ episode of FS less than 1 year, duration of fever, grade of fever, family history of FS and epilepsy, male gender and complex febrile seizure as initial seizure were not found to be significantly associated with recurrence of FS. No significant association between the numbers of risk factors and recurrence of FS was found. Prescribing prophylaxis for FS statistically did not show any benefit in decreasing the frequency nor completely stop the recurrences of FS.

\section{REFERENCES:}

1. Subcommittee on Febrile Seizures, American Academy of Pediatrics. Neurodiagnostic evaluation of the child with a simple febrile seizure. Pediatrics. 2011 Feb; 127(2): p. 389-94.

2. Mikati MA. Febrile Seizures. In Kliegman RM, Stanton BF, St. Geme III JW, Schor NF, Behrman RE, editors. Nelson Textbook of Pediatrics. 19th ed. Philadelphia: Elsevier, Saunders; 2011. p. 2013-39.

3. Nelson KB, Ellenberg JH. Predictors of epilepsy in children who have experiened febrile seizures. N Engl J Med. 1976; 295(19): p. 1029-33.

4. Hauser WA. The prevalence and incidence of convulsive disorders in children. Epilepsia. 1994; 35: p. 1-6.

5. Mittal R. Febrile seizures. In Parthasarathy A, Menon P, Gupta P, Nair M, Agarwal R, Sukumaran T, editors. IAP Textbook of Pediatrics. 5th ed. New Delhi: Jaypee Brothers Medical Publishers (P) LTD; 2013. p. 335-7.

6. Hackett R, Hackett L, Bhakta P. Febrile seizures in a south Indian district: incidence and association. Dev Med Child Neurol. 1997; 39: p. 380-4.

7. Goel D, Agarwal A, Dhanai JS, Semval VD, Mehrotra V, Saxena V, et al. Comprehensive rural epilepsy surveillance programme in uttarakhand state of India. Neurol India. 2009; 57: p. 355-6.
8. Mani KS, Rangan G, Srinivas HV, Kalyanasundaram S, Narendran S, Reddy AK. The yelandur study: a communitybased approach to epilepsy in rural south Indiaepidemiological aspects. Seizure. 1998; 7: p. 281-8.

9. Bessisso MS, Elsaid MF, Almula NA, Kadomi NK, Zeidan SH, Azzam SB, et al. Recurrence risk after a first febrile convulsion. Saudi Med J. 2001; 22(3): p. 254-8.

10. Rantala $H$, Uhari M. Risk factors for recurrences of febrile convulsion. Acta Neurol Scand. 1994; 90(3): p. 207-10.

11. Laditan AA. Seizure recurrence after a first febrile convulsion. Annual Tropical Paediatrics. 1994; 14(4): p. 303-8.

12. Al-Eissa YA. Febrile seizure: rate and risk factors of recurrence. J Child neurol. 1995; 10(4): p. 315-9.

13. Shinnar S. Febrile seizures. In Swaiman KF, Ashwal S, Ferriero DM, editors. Pediatric Neurology: Principles and practice. 4th ed. Philadelphia: Mosby Elevier; 2006. p. 1078-86.

14. Waruiru C, Appleton R. Febrile seizures: an update. Archives of Disease in Childhood. 2004; 89: p. 751-6.

15. Leung AK, Robson WL. Febrile seizures. Journal of Paediatric Health Care. 2007; 21(4): p. 250-5.

16. Sadleir LG, Scheffer IE. Febrile seizures. BMJ. 2007; 334: p. 307-11.

17. Martin-Fernandez JJ, Molto-Jorda JM, Villaverde R, Salmeron P, Prieto-Munoz I, Fernández-Barreiro A. Risk factors in recurrent febrile seizures. Rev Neurol. 1996; 24(136): p. 1520-24.

18. Offringa M, Bossuyt PM, Lubsen J, Ellenberg JH, Nelson KB, Knudsen FU, et al. Risk factors for seizures recurrence in children with febrile seizures: a pooled analysis of individual patient data from five studies. Pediatr. 1994; 124(4): p. 578-84.

19. Berg AT, Shinnar S, Darefsky AS, Holford TR, Shapiro ED. Predictors of recurrent febrile seizures. A prospectie cohort study. Arch Pediatr Adolesc Med. 1997; 151: p. 3718.

20. Nelson, Karin B, Ellenberg, Jones H. Prognosis in children with febrile. Pediatrics. 1978; 61: p. 720-7.

21. Rutter N, Smales ORC. Role of routine investigations in children presenting with their first febrile convulsions. Arch. Dis. Child. 1977; 52: p. 188-91.

22. Fallah R, Akhavan KS. Recurrence of febrile seizure in Yazd, Iran. Turkish Journal of Pediatrics. 2010; 52: p. 618622.

Ojha AR, Shakya KN, Aryal UR. Recurrence Risk of Febrile Seizures in Children. J. Nepal Paediatr.

23. Ojha AR, Shakya KN, Aryal UR. Recurrence Risk of Febrile Seizures in Children. J. Nepal Paediatr. Soc. 2012; 32(1): p. 33-6.

24. Chan KK, Cherk S, Chan $\mathrm{CH}, \mathrm{Ng}$ D, Ho J. A Retrospective Review of First Febrile Convulsion and Its Risk Factors for Recurrence in Hong Kong Children. HK J Paediatr (New Series). 2007; 12: p. 181-7.

25. Talebian A, Mohammadi M. Febrile seizure: recurrence and risk factors. Iranian J child neurology. 2006; 1(1): p. 43-6. 
26. Eseigbe EE, Adama SJ, Eseigbe P. Febrile seizures in Kaduna, north western Nigeria. Niger Med J. 2012; 53(3): p. 140-4.
27. Berg AT, Shinnar S, Hauser WA, Alimany M, Eugene D, Morton E. A prospective study of recurrent febrile seizures. N Eng J Med. 1992; 327: p. 1161-3.

\begin{tabular}{|c|c|c|c|c|}
\hline $\begin{array}{c}\text { Risk } \\
\text { Factors }\end{array}$ & Variables & $\begin{array}{c}\text { Number of } \\
\text { Subjects (63) }\end{array}$ & $\begin{array}{c}\text { With } \\
\text { Recurrence (46) }\end{array}$ & $\begin{array}{c}\text { p- } \\
\text { value }\end{array}$ \\
\hline \multirow{5}{*}{ Age (Months) } & $\leq 12$ & 8 & 3 & \multirow{5}{*}{0.004} \\
\hline & $13-24$ & 10 & 6 & \\
\hline & $25-36$ & 16 & 16 & \\
\hline & $37-48$ & 13 & 8 & \\
\hline & $49-60$ & 16 & 13 & \\
\hline \multirow{2}{*}{ Sex } & Male & 28 & 20 & \multirow{2}{*}{0.999} \\
\hline & Female & 35 & 26 & \\
\hline \multirow{2}{*}{ Parental consanguinity } & Yes & 14 & 14 & \multirow{2}{*}{0.013} \\
\hline & No & 49 & 32 & \\
\hline \multirow{2}{*}{ Duration of fever } & $<24$ hrs. & 33 & 23 & \multirow{2}{*}{0.581} \\
\hline & $>24$ hrs. & 30 & 23 & \\
\hline \multirow{2}{*}{ Type of FS } & Simple & 49 & 33 & \multirow{2}{*}{0.088} \\
\hline & Complex & 14 & 13 & \\
\hline \multirow{2}{*}{ Family history of febrile seizure } & Yes & 27 & 22 & \multirow{2}{*}{0.255} \\
\hline & No & 36 & 24 & \\
\hline \multirow{2}{*}{ Family history of Epilepsy } & Yes & 13 & 8 & \multirow{2}{*}{0.311} \\
\hline & No & 50 & 38 & \\
\hline
\end{tabular}

